\title{
Adherence and persistence to typical and atypical antipsychotics in the naturalistic treatment of patients with schizophrenia
}

\author{
Haya Ascher-Svanum' \\ Baojin Zhu' \\ Douglas E Faries' \\ Jonathan $\mathrm{P}$ Lacro ${ }^{2}$ \\ Christian R Dolder ${ }^{3}$ \\ Xiaomei Peng' \\ 'Eli Lilly and Company, Outcomes \\ Research, Indianapolis, IN, USA; \\ ${ }^{2}$ VA San Diego Health Care System \\ and Department of Psychiatry, \\ University of California, San Diego, \\ CA, USA; ${ }^{3}$ Wingate University School \\ of Pharmacy, Wingate, NC, USA
}

\begin{abstract}
Objective: To compare adherence and persistence to typical versus atypical antipsychotics and between specific atypical agents in the usual care of schizophrenia and to examine the association between adherence and persistence.

Method: Data were drawn from a 3-year prospective, nonrandomized, noninterventional study of schizophrenia conducted during 1997-2003. Initiators on haloperidol, risperidone, olanzapine, quetiapine, and clozapine with at least 1 year of follow-up were included $(n=878)$. Adherence (Medication Possession Ratio, MPR) and persistence (time to all-cause medication discontinuation) were assessed using medical record prescription information. Analyses employed multivariate statistics adjusted for group differences.

Results: Overall, $58 \%$ of the patients were deemed adherent (MPR $>80 \%$ ). Adherence rates were higher: for atypical (59.4\%) than typical antipsychotics $(34.5 \%, \mathrm{p}<0.001)$, for clozapine $(77 \%)$ than each comparator excluding olanzapine $(\mathrm{p}<0.01)$, and for olanzapine $(64 \%)$ than risperidone $(57 \%, \mathrm{p}=0.027)$ and quetiapine $(52 \%, \mathrm{p}=0.019)$. Differences between risperidone and quetiapine were not statistically significant. Adherence and persistence were highly correlated $(\mathrm{r}=0.957, \mathrm{p}<0.001)$.

Conclusion: In the usual care of schizophrenia, medication adherence and persistence appear to be highly correlated and to significantly differ between typical and atypical antipsychotics and among atypical agents. The choice of antipsychotic may play a meaningful role in patients' adherence to and persistence with antipsychotic medications.
\end{abstract}

Keywords: adherence, persistence, schizophrenia, antipsychotics

\section{Introduction}

In the treatment of schizophrenia, poor adherence with antipsychotic medication is known to raise personal burden and economic cost (Fenton et al 1997) by increasing the risk of relapse, hospitalizations (Fenton et al 1997; Valenstein et al 2002; Gilmer et al 2004; Weiden et al 2004; Ascher-Svanum et al 2006a), and poorer functional outcomes, including arrests and violent behaviors (Swanson et al 2004a, b; AscherSvanum et al 2006a). The risk of nonadherence with antipsychotic regimens is affected by factors that are broadly categorized as patient, environment, and treatment-related risk factors (Kampman and Lehtinen 1999). Among the treatment-related risk factors is choice of the antipsychotic agent.

Differences between typical and atypical antipsychotics have been extensively studied and are the topic of ongoing debate whether some atypical antipsychotics are more effective than others and whether atypicals are more effective than typical antipsychotics (Geddes et al 2000; Rosenheck et al 2003; Jones et al 2006; Rosenheck 2006). When compared on level of medication adherence, schizophrenia patients treated with typical antipsychotics were often found (Cabeza et al 2001; Svarstad et al 2001; 
Al-Zarkawi et al 2003; Menzin et al 2003; Mojtabai et al 2003; Opolka et al 2003; Garcia-Gibson et al 2004), but not always (Dolder et al 2002; Diaz et al 2004; Gilmer et al 2004; Valenstein et al 2004), to have poorer adherence compared to patients treated with atypicals. When comparing adherence between atypical agents, several studies reported greater adherence to specific atypical antipsychotics versus other atypicals (eg, to olanzapine vs risperidone) (Garcia-Cabeza et al 2001; Zhao et al 2002; Opolka et al 2003; Rascati et al 2003; Diaz et al 2004; Gibson et al 2004), whereas other studies did not (Dolder et al 2002; Gilmer et al 2004; Valenstein et al 2004).

In contrast with the inconclusive findings on differential adherence to various antipsychotics, previous findings on medication persistence with antipsychotics have been relatively consistent, often showing better persistence on atypical than typical antipsychotics (Revicki et al 1999; Glick and Berg 2002; Leucht et al 2003; Lieberman et al 2003; Dossenbach et al 2004; Kemmler et al 2005; Ascher-Svanum et al 2006b; Tiihonen et al 2006; Tunis et al 2006; Beasley et al 2007; Cooper et al 2007; Haro et al 2007) and better persistence with a specific atypical (olanzapine) when compared to other atypicals such as risperidone, quetiapine, ziprasidone, and aripiprazole (PhRMA aripiprazole; Gilbody et al 2000; Ren et al 2002; Bagnall et al 2003; Santarlasci and Messori 2003; Dossenbach et al 2004; Pelagotti et al 2004; Simpson et al 2004; Breier et al 2005; Mudge et al 2005; Kinon et al 2006a, b; Tunis et al 2006; Cooper et al 2007; Haro et al 2007; Jayaram et al 2007; Mullins et al 2007; Strom et al 2007).

Differences in persistence among atypical antipsychotics were also observed in the NIMH-sponsored CATIE schizophrenia study (Lieberman et al 2005; McEvoy et al 2006; Stroup et al 2006), a large, 18-month, double-blind, randomized study comparing 5 antipsychotics: a medium potency typical antipsychotic (perphenazine) and 4 atypical antipsychotics (olanzapine, risperidone, quetiapine, ziprasidone). Persistence, as measured by time to all-cause medication discontinuation, was assumed to reflect a medication's efficacy, safety, and tolerability from both patient and clinicians' perspectives (Stroup et al 2003; Lieberman et al 2005). The primary phase of the CATIE, Phase 1, found significantly longer time to all-cause medication discontinuation on olanzapine compared to risperidone and quetiapine. Treatment duration on olanzapine did not significantly differ from ziprasidone or perphenazine as the initially significant differences favoring olanzapine turned nonsignificant following adjustment for multiple comparisons. In a second phase of CATIE (phase 2E; McEvoy et al 2006), which included patients who discontinued Phase 1 due to lack of medication efficacy, persistence in therapy was significantly longer for clozapine than quetiapine or risperidone, but not compared to olanzapine. Furthermore, in CATIE phase 2T (Stroup et al 2006), which included patients who discontinued Phase 1 due to medication intolerability or lack of efficacy, persistence in therapy was longer for patients treated with risperidone and olanzapine compared to quetiapine and ziprasidone. In addition, for patients who discontinued their previous antipsychotic because of inefficacy, persistence on olanzapine therapy was longer than for quetiapine and ziprasidone and for risperidone longer than quetiapine.

Although adherence and persistence with antipsychotics have been extensively examined using multiple methodologies, they have been studied separately in different patient populations (Cooper et al 2007). As a result, no information is available on the potential correspondence between patients' adherence and persistence on the same medications in the treatment of schizophrenia. The only study that assessed both persistence and adherence with atypical antipsychotics in the same population (Cooper et al 2007) did not assess concordance between the adherence and persistence measures and focused on adherence with specific atypical antipsychotics among patients who were deemed persistent with any atypical antipsychotic regimen. That study found differential persistence among the atypicals (greater likelihood of persistence with clozapine and olanzapine than with risperidone), but no differentiation on adherence among the persistent patients.

The present study aimed to expand on previous research and assess differences in medication adherence and persistence to typical versus atypical antipsychotics and to specific atypical agents in the usual care of patients with schizophrenia. A secondary objective was to examine the concordance between patients' adherence and persistence with the same antipsychotics. Using prescription data from a large, 3-year prospective, naturalistic, nonrandomized, noninterventional, multisite study of patients treated for schizophrenia in the US, we identified patients who were initiated on typical (haloperidol) or atypical (clozapine, olanzapine, risperidone, or quetiapine) antipsychotics at any time in the study and had been followed up for at least 1 year post-initiation. We expected adherence and persistence to be highly interrelated, and based on previous research on persistence with antipsychotics in the treatment of schizophrenia (Gilbody et al 2000; Ren et al 2000; Bagnall et al 2003; Lieberman et al 2003; Leucht et al 2003; Santarlasci and Messori 2003; Pelagotti 
et al 2004; Simpson et al 2004; Dossenbach et al 2004; Breier et al 2005; Lieberman 2005; Stroup 2006; McEvoy 2006; Kinon et al 2006a, b; Tunis et al 2006; Tiihonen et al 2006; Haro et al 2007; Cooper et al 2007; Mullins et al 2007) we hypothesized that the 4 atypicals are superior to the typical antipsychotic haloperidol on persistence and adherence and that clozapine and olanzapine therapy would differentiate themselves among the 4 atypical agents with greater adherence and persistence.

\section{Methods}

\section{Data source}

We used data from the Lilly-sponsored Schizophrenia Care and Assessment Program (US-SCAP), a large $(\mathrm{n}=2327)$, 3-year, naturalistic, prospective, nonrandomized noninterventional study in the US that was conducted between 7/1997 and 9/2003 (Faries et al 2005; Ascher-Svanum et al 2004, 2006a, b). The goal of US-SCAP was to understand the treatment of patients with schizophrenia in "real world" settings. Approximately 400 patients at each of the study's 6 regional sites were enrolled. All patients were diagnosed with schizophrenia, schizoaffective, or schizophreniform disorders based on DSM-IV criteria and were at least 18 years of age. Patients were excluded if they were unable to provide informed consent or had participated in a clinical drug trial within 30 days prior to enrollment. Of 3332 patients who met inclusion criteria, 765 (23.0\%) refused, and 240 (7.2\%) were not enrolled due to other reasons. Most enrollees completed 1 year of follow-up (78.1\%), with fewer patients completing 2 years $(69.6 \%)$ and 3 years $(65.2 \%)$.

Enrollment was not contingent upon being treated with a specific antipsychotic or with any medication. Patients could continue with medications they were prescribed prior to enrollment for as long as necessary, and decisions about changes in medications during the study, if any, were made by physicians and their patients as occurs in usual practice.

Patients were enrolled from 6 states (California, Colorado, Connecticut, Florida, Maryland, and North Carolina) and represented treatment in diverse systems of care including community mental health centers, university health care systems, the Department of Veterans Affairs Health Services (VA), and community and state hospitals. Institutional Review Board (IRB) approval was received at each regional site, and informed consent was received from all patients. Further details about US-SCAP are available elsewhere (Faries et al 2005; Ascher-Svanum et al 2006a, b).

The present study included patients who were initiated at any time during the 3-year study on haloperidol, clozapine, risperidone, olanzapine, or quetiapine in standard oral formulation. Treatment group membership was based on the first initiated medication at any time in the study. These patients did not receive the index medication in the 60 days prior to initiation and had at least 1 year of follow-up after initiation. Reflecting usual clinical practice, patients could be augmented with other typical and/or atypical antipsychotics (antipsychotic polypharmacy), in any formulation at any time per physician's decision. Patients initiated on ziprasidone or aripiprazole were excluded from the analysis due to small sample size.

\section{Measures}

Interviews with the patients at enrollment provided information about socio-demographic characteristics and psychiatric history. Starting at enrollment, medical records were systematically abstracted for each prior 6-month interval for every patient using a medical resource abstraction form that was developed for this study.

Patients' medical records provided information about each psychiatric hospitalization (admission and discharge dates) and about prescribed psychiatric medication (medication name, dose, frequency, start and stop dates, and route of administration). Patients were queried about use of medications and other psychiatric resources outside of those provided at their regular treatment site. When this occurred, systematic efforts were made to abstract out-of-site medical records.

Consistent with prior research (Valenstein et al 2002; Weiden et al 2004), adherence was assessed with the Medication Possession Ratio (MPR), the percent of total cumulative days with the index medication during the 365 days following its initiation. Higher values indicate better adherence with the prescribed antipsychotic medication. Poor adherence, often defined as MPR $\leq 80 \%$, was previously found to be associated with a high risk of psychiatric hospitalizations (Valenstein et al 2002; Thieda et al 2003; Ascher-Svanum et al 2006a), emergency services, arrests, violent behaviors, substance use, and other unfavorable outcomes (Thieda et al 2003; Ascher-Svanum et al 2006a). Adherence was defined as MPR $>80 \%$, a threshold used in past research to assess adherence with antipsychotics in the treatment of schizophrenia (Dolder et al 2002; Gilmer et al 2004; Valenstein et al 2002, 2004; Elbogen et al 2005). The MPR was used to calculate mean adherence rates (continuous MPR) and the proportion of adherent patients (MPR $>80 \%$ ) in each treatment group.

Although MPR is commonly used to quantify medication use in pharmacy claims databases, the MPR in this study was based on prescription information in medical 
records. Since no pharmacy claim data were collected in US-SCAP, the rate of prescription fill is unknown. However, prior research in this population (Svarstad et al 2001) has shown a high level of correspondence between medication prescription in medical records and pharmacy fill rate.

Persistence with the index antipsychotic drug was defined as the time to medication discontinuation for any cause and calculated as the number of consecutive days from initiation of the index drug to the start of the first medication gap of $>30$ days during the 1-year following initiation (Ren et al 2002; Zhao et al 2002; Mojtabai et al 2003; Gibson et al 2004). A gap could have resulted from any number of events, including switching to another drug or discontinuation of the drug. Although several studies have used the criterion of $>14$ consecutive days without medication as an indicator of drug discontinuation, we took a more conservative approach and used a larger medication gap size. Past research has shown consistent findings when using 14 or 30 days to define medication discontinuation in the treatment of schizophrenia (Ascher-Svanum et al 2006b). In addition to mean time to medication discontinuation, the proportion of patients completing at least 1 year of treatment on the initiated antipsychotic was also measured.

\section{Statistical analysis}

Group comparisons on socio-demographic and treatment characteristics prior to initiation on the "index" antipsychotic medication were made using chi-square tests for categorical variables and ANOVA for continuous variables. To compare medication groups on adherence, we performed linear and logistic regression models after square root transformation of the MPR due to its skewed distribution (Box and Cox 1964). These analyses controlled for patient socio-demographics (age, sex, ethnicity), illness duration, and treatment variables on which the treatment groups were found to significantly differ during the 2 months prior to initiation of the index medication (psychiatric hospitalization [yes/no] and use [yes/no] of: oral antipsychotics, depot typical antipsychotics, mood stabilizers, and antipsychotic polypharmacy). To check the robustness of the findings, analyses were repeated controlling also for potential "time period bias" in the regression analysis, because atypical antipsychotics were introduced in the US over several years. To that end, we calculated for each patient the time (days) elapsed between the study start (7/1/1997) and the initiation date on the index medication.

Treatment group comparisons on the mean continuous MPR, proportion of adherent patients per MPR $>80 \%$, mean time to medication discontinuation for any cause, and proportion of patients completing at least 1 year on the index medication were performed for the typical (haloperidol) versus atypicals (clozapine, risperidone, olanzapine, quetiapine, combined), for the typical versus each of the 4 atypicals, and pair-wise comparisons between the atypicals. To compare medication groups on the proportion of adherent patients (MPR > 80\%), we used logistic models with adjustments for covariates noted above. To assess the robustness of the findings, we repeated the latter analysis using 7 other adherence thresholds that dichotomized the MPR into adherent and nonadherent, including MPR $>60 \%, 65 \%, 70 \%, 75 \%$, $85 \%, 90 \%$, and $95 \%$.

To assess the concordance between the adherence and persistence measures, we calculated Pearson productmoment correlation between the continuous MPR measure and time (days) to all-cause medication discontinuation. Treatment group comparisons on persistence levels employed Cox Proportional Hazard Model, adjusted for covariates used in the adherence analyses.

Although all patients have undergone clinical assessments with standard measures at enrollment and every 12 months thereafter, these assessments were not set to coincide with the time of initiation or discontinuation of any drug. These clinical measures were not used in this study to control for treatment group differences, because the assessments did not reflect patients' clinical status at the time of initiation on the medication. All statistical tests were 2-tailed, and significance was set at alpha of 0.05 .

\section{Results}

\section{Patient characteristics}

This study included patients $(n=878)$ who were initiated on haloperidol $(n=110)$, clozapine $(n=74)$, risperidone $(n=235)$, olanzapine $(n=347)$, and quetiapine $(n=112)$. At the time of initiation on the index medication, the treatment groups significantly differed on age, ethnicity, illness duration, and on the following variables in the 60 days prior to initiation on the index antipsychotic: psychiatric hospitalization, use of antipsychotics in oral formulation, antipsychotics in depot formulation, antipsychotic polypharmacy, and mood stabilizers (Table 1). Treatment groups also differed on time to initiation on the index medication from the date of the study start. Expectedly, quetiapine-treated patients had longer time to medication initiation since quetiapine was launched in the US later (1997) than clozapine (1990), risperidone (1994), and olanzapine (1996). The mean daily doses (SD) of the index antipsychotics were: $8.8 \mathrm{mg}(6.8 \mathrm{mg})$ for haloperidol, $368.9 \mathrm{mg}$ (164.2 mg) for clozapine, $4.1 \mathrm{mg}$ 
Table I Patient characteristics by treatment group ${ }^{a}$

\begin{tabular}{|c|c|c|c|c|c|}
\hline Characteristic & $\begin{array}{l}\text { Haloperidol } \\
\mathrm{n}=1 \mathrm{I} 10\end{array}$ & $\begin{array}{l}\text { Risperidone } \\
\mathrm{n}=\mathbf{2 3 5}\end{array}$ & $\begin{array}{l}\text { Olanzapine } \\
n=347\end{array}$ & $\begin{array}{l}\text { Quetiapine } \\
\mathrm{n}=\mathbf{I} \mathbf{2}\end{array}$ & $\begin{array}{l}\text { Clozapine } \\
\mathrm{n}=74\end{array}$ \\
\hline Age, mean (SD) ${ }^{b}$ & $37.9(9.6)$ & $41.8(12.5)$ & $43.3(10.8)$ & $40.6(I I .2)$ & $38.6(8.9)$ \\
\hline Illness duration in years, mean (SD) ${ }^{\mathrm{b}}$ & $18.5(10.9)$ & $21.3(12.6)$ & $23.3(11.8)$ & $19.6(11.1)$ & $20.0(10.1)$ \\
\hline Male (\%) & 55.5 & 54.9 & 61.1 & 47.3 & 62.2 \\
\hline \multicolumn{6}{|l|}{ Race $(\%)^{b}$} \\
\hline White & 30.9 & 46.8 & 49.9 & 50.9 & 62.2 \\
\hline Black & 48.2 & 38.7 & 38.3 & 35.7 & 23.0 \\
\hline Other & 20.9 & 14.5 & 11.8 & 13.4 & 14.9 \\
\hline High school education or less (\%) & 59.1 & 69.2 & 65.3 & 74.6 & 73.0 \\
\hline \multicolumn{6}{|l|}{ Diagnosis (\%) } \\
\hline Schizoaffective & 34.6 & 32.8 & 32.3 & 39.3 & 35.1 \\
\hline Schizophrenia, paranoid & 36.4 & 38.7 & 42.9 & 32.1 & 40.5 \\
\hline Schizophrenia, undifferentiated & 19.1 & 16.2 & 15.9 & 15.2 & 18.9 \\
\hline Other & 10.0 & 12.3 & 8.9 & 13.4 & 5.41 \\
\hline \multicolumn{6}{|l|}{ Health Insurance (\%) } \\
\hline Medicaid/Medicare/Medicaid and Medicare & 76.9 & 79.8 & 81 & 83.6 & 86.5 \\
\hline CHAMPUS (Department of Defense) & 4.6 & 5.6 & 7.9 & 2.7 & 5.4 \\
\hline Privately insured & 5.6 & 3.9 & 2.6 & 2.7 & 1.4 \\
\hline Other & 1.9 & 1.3 & 0.6 & 1.8 & 1.4 \\
\hline No insurance & II.I & 9.4 & 7.9 & 9.1 & 5.4 \\
\hline $\begin{array}{l}\text { Time to initiation on index medication, mean } \\
\text { days (S.D.) }\end{array}$ & $515.6(340.9)$ & $640.5(327.1)$ & $599(333.1)$ & $834.3(3 \mid 5.3)$ & $618.7(349.4)$ \\
\hline Prior psychiatric hospitalization (\%) ${ }^{\mathrm{b}, \mathrm{c}}$ & 38.2 & 22.6 & 17.0 & 15.2 & 35.1 \\
\hline \multicolumn{6}{|l|}{ Prior medication Use ${ }^{c}$} \\
\hline Oral antipsychotics ${ }^{\mathrm{b}}$ & 43.6 & 70.6 & 71.5 & 88.4 & 82.4 \\
\hline Typical depot antipsychotics ${ }^{b}$ & 33.6 & 16.6 & 21.3 & 13.4 & 21.6 \\
\hline Mood stabilizers ${ }^{\mathrm{b}}$ & 29.1 & 20.9 & 31.7 & 37.5 & 37.8 \\
\hline Antipsychotic polypharmacy ${ }^{\mathrm{b}}$ & 8.2 & II.I & 6.1 & 24.1 & 24.3 \\
\hline
\end{tabular}

aPercentages listed unless otherwise specified.

bSignificant groups difference at $\mathrm{p}<0.05$.

'During the 60 days prior to initiation on the index drug.

(2.4 mg) for risperidone, $13.7 \mathrm{mg}$ (7.3 $\mathrm{mg}$ ) for olanzapine, and $331.6 \mathrm{mg}(210.9 \mathrm{mg})$ for quetiapine.

\section{Adherence Mean MPR}

The mean MPR for all patients was $70.9 \%$. As presented in Table 2, the mean MPR was significantly higher for patients treated with atypical antipsychotics (MPR $=73.6 \%)$ compared to haloperidol (MPR $=52.0 \%, \mathrm{p}<0.001)$ and for patients treated with each atypical compared to haloperidol $(p<0.001)$. Significantly higher mean adherence rate was found for patients treated with clozapine (MPR $=83.5 \%$ ) compared to risperidone (MPR $=70.0 \%, \mathrm{p}=0.024)$ and quetiapine $(M P R=66.2 \%, p=0.022)$. Significantly higher mean adherence rate was found for patients treated with olanzapine (MPR $=76.3 \%)$ compared to risperidone ( $\mathrm{MPR}=70.0 \%$, $\mathrm{p}=0.008)$ and quetiapine (MPR $=66.2 \%, \mathrm{p}=0.005)$. Differences between risperidone and quetiapine $(p=0.538)$ and between clozapine and olanzapine $(p=0.648)$ therapy were not statistically significant.

\section{Proportion of adherent patients}

Overall, $58 \%$ of the patients were deemed adherent (MPR $>80 \%$ ). A significantly greater proportion of atypical antipsychotic-treated patients were adherent compared to the haloperidol-treated group (61.1\% vs $34.5 \%$, p < 0.001$)$ (Table 2). Among the atypical agents, a significantly larger proportion of clozapine-treated patients were adherent compared to risperidone $(77.0 \%$ vs $56.6 \%, \mathrm{p}<0.01)$ and quetiapine (77.0\% vs $51.8 \%, \mathrm{p}<0.01)$, but not compared to olanzapine ( $77.0 \%$ vs $63.7 \%, \mathrm{p}>0.05)$. A significantly larger proportion of olanzapine-treated patients were adherent compared to patients treated with risperidone $(63.7 \%$ vs $56.6 \%, \mathrm{p}=0.027)$ and quetiapine $(63.7 \%$ vs $51.8 \%, \mathrm{p}=0.019)$. The difference between risperidone and quetiapine-treated patients was not statistically significant $(56.6 \%$ vs $51.8 \%, \mathrm{p}=0.305)$.

\section{Sensitivity analyses}

To assess robustness of the findings, we repeated the analysis using 7 additional MPR thresholds to define adherence with 
Table 2 Adherence and persistence in the I-year post initiation by treatment group

\begin{tabular}{|c|c|c|c|c|}
\hline \multirow[t]{2}{*}{ Treatment group } & \multicolumn{2}{|l|}{ Adherence } & \multicolumn{2}{|l|}{ Persistence } \\
\hline & $\begin{array}{l}\text { Mean (SD) } \\
\text { MPR\% }\end{array}$ & $\begin{array}{l}\text { Proportion adherent } \\
\text { (MPR }>80 \%)\end{array}$ & $\begin{array}{l}\text { Mean(SD) time to all-cause } \\
\text { discontinuation }\end{array}$ & $\begin{array}{l}\text { Proportion } \\
\text { persistent }\end{array}$ \\
\hline \multirow[t]{2}{*}{ Atypicals, combined vs HAL } & $73.6(35.0)^{c}$ & $61.1^{c}$ & $260.7(136.0)^{c}$ & $53.9^{c}$ \\
\hline & $52.0(37.9)$ & 34.5 & $173.9(144.5)$ & 22.7 \\
\hline \multirow[t]{2}{*}{ CLO vs OLZ } & $83.5(31.6)$ & 77 & $305.46(114.4)$ & 71.6 \\
\hline & $76.3(33.3)$ & 63.7 & 271.7 (I29.7) & 56.5 \\
\hline \multirow[t]{2}{*}{ CLO vs RIS } & $83.5(31.6)^{\mathrm{a}}$ & $77^{\mathrm{b}}$ & $305.46(114.4)^{b}$ & $71.6^{\mathrm{b}}$ \\
\hline & $70.0(36.5)$ & 56.6 & $245.1(142.2)$ & 48.5 \\
\hline \multirow[t]{2}{*}{ CLO vs QUE } & $83.5(31.6)^{\mathrm{a}}$ & $77^{\mathrm{b}}$ & $305.46(114.4)^{b}$ & $71.6^{\mathrm{b}}$ \\
\hline & $66.2(37.0)$ & 51.8 & $230.2(145.2)$ & 45.5 \\
\hline \multirow[t]{2}{*}{ CLO vs HAL } & $83.5(31.6)^{c}$ & $77^{c}$ & $305.46(114.4)^{c}$ & $71.6^{c}$ \\
\hline & $52.0(37.9)$ & 34.5 & $173.9(\mid 44.5)$ & 22.7 \\
\hline \multirow[t]{2}{*}{ OLZ vs RIS } & $76.3(33.3)^{b}$ & $63.7^{\mathrm{a}}$ & $271.7(129.7)^{\mathrm{a}}$ & $56.5^{\mathrm{a}}$ \\
\hline & $70.0(36.5)$ & 56.6 & $245.1(142.2)$ & 48.5 \\
\hline \multirow[t]{2}{*}{ OLZ vs QUE } & $76.3(33.3)^{\mathrm{b}}$ & $63.7^{\mathrm{a}}$ & $271.7(129.7)^{\mathrm{b}}$ & $56.5^{\mathrm{a}}$ \\
\hline & $66.2(37.0)$ & 51.8 & $230.2(145.2)$ & 45.5 \\
\hline \multirow[t]{2}{*}{ OLZ vs HAL } & $76.3(33.3)^{c}$ & $63.7^{c}$ & $271.7(129.7)^{c}$ & $56.5^{c}$ \\
\hline & $52.0(37.9)$ & 34.5 & I73.9 (I44.5) & 22.7 \\
\hline \multirow[t]{2}{*}{ RIS vs QUE } & $70.0(36.5)$ & 56.6 & $245.1(142.2)$ & 48.5 \\
\hline & $66.2(37.0)$ & 51.8 & $230.2(145.2)$ & 45.5 \\
\hline \multirow[t]{2}{*}{ RIS vs HAL } & $70.0(36.5)^{c}$ & $56.6^{\mathrm{b}}$ & $245.1(142.2)^{c}$ & $48.5^{c}$ \\
\hline & $52.0(37.9)$ & 34.5 & I73.9 (I44.5) & 22.7 \\
\hline \multirow[t]{2}{*}{ QUE vs HAL } & $66.2(37.0)^{b}$ & $51.8^{\mathrm{a}}$ & $230.2(145.2)^{\mathrm{a}}$ & $45.5^{\mathrm{a}}$ \\
\hline & $52.0(37.9)$ & 34.5 & $173.9(\mid 44.5)$ & 22.7 \\
\hline
\end{tabular}

Sample size: Haloperidol $n=110$; OLZ $n=347$; RIS $n=235$; QUE $n=112$; CLO $n=74$.

Adherent defined as MPR $\geq 80 \%$; Persistent defined as completing I year of treatment on the index drug.

aSignificant groups difference at $p<0.05$.

bSignificant groups difference at $p<0.01$

'Significant groups difference at $\mathrm{p}<0.001$.

Abbreviations: MPR, medication possession ratio; CLO, clozapine; HAL, haloperidol; OLZ, olanzapine; QUE, quetiapine; RIS, risperidone.

cutoff values ranging from MPR $>60 \%$ to MPR $>95 \%$ in $5 \%$ increments. Table 3 presents the proportion of adherent patients by treatment group and the associated $p$ values from the logistic regression, demonstrating the robustness of the findings across the 8 variations on the definition of adherence. Results were also essentially unchanged when the analyses were repeated with additional control for potential "time period bias".

\section{Persistence}

Mirroring the adherence-related findings (Table 2), persistence, as measured by time to all-cause medication discontinuation (days), was significantly shorter for haloperidol (173.9) than for the combined atypical antipsychotic treatment groups $(260.7, \mathrm{p} \leq 0.001)$ and differed between the atypical antipsychotics in descending order: clozapine (305.46), olanzapine (271.66), risperidone (245.07), and quetiapine (230.19). The same descending order was found when using the proportion of patients completing at least 1 year of treatment on the initiated medication: clozapine (71.6\%), olanzapine (56.5\%), risperidone $(48.5 \%)$, quetiapine $(45.5 \%)$, and haloperidol
(22.7\%). The proportion of patients completing at least 1 year of treatment on the index medication was significantly higher for patients treated with atypicals, in aggregate, compared to the typical ( $\mathrm{p}<0.001)$, and for clozapine compared to haloperidol $(\mathrm{p}<0.001)$, risperidone $(\mathrm{p}=0.002)$, and quetiapine $(p=0.004)$, but not compared to olanzapine $(p=0.052)$. The olanzapine group had a significantly higher treatment completion rate compared to haloperidol ( $\mathrm{p}<0.001)$, risperidone $(p=0.033)$, and quetiapine $(p=0.029)$. The risperidone group had significantly higher treatment completion rates than haloperidol $(\mathrm{p}<0.001)$, but not compared to quetiapine $(p=0.313)$. The quetiapine significantly differed only from haloperidol $(\mathrm{p}=0.015)$.

Using the Cox Proportional Hazard Model, the haloperidoltreated group was found to be more likely to discontinue the medication compared to the atypical-treated patients (hazard ratio $[\mathrm{HR}]=2.31,95 \%$ confidence interval $[\mathrm{CI}]$ $1.78-3.01, \mathrm{p}<0.001)$. The olanzapine-treated patients were more likely to discontinue than clozapine ( $\mathrm{HR}=1.65,95 \%$ CI 1.01-2.71, $\mathrm{p}=0.047)$. The risperidone-treated patients were more likely to discontinue than clozapine $(\mathrm{HR}=2.09$, 
Table 3 Differences between treatment groups on proportion of adherent patients using 8 different MPR thresholds to define adherence

\begin{tabular}{|c|c|c|c|c|c|c|c|c|}
\hline \multirow[t]{2}{*}{ Treatment groups } & \multicolumn{8}{|c|}{ MPR threshold (\%) } \\
\hline & $>60 \%$ & $>65 \%$ & $>70 \%$ & $>75 \%$ & $>80 \%$ & $>85 \%$ & $>90 \%$ & $>95 \%$ \\
\hline \multirow[t]{2}{*}{ Atypicals, combined vs HAL } & $67.7^{c}$ & $66.0^{c}$ & $64.1^{c}$ & $62.8^{c}$ & $61.1^{c}$ & $59.2^{c}$ & $57.8^{c}$ & $56.5^{c}$ \\
\hline & 42.7 & 41.8 & 38.2 & 37.3 & 34.5 & 29.1 & 29.1 & 24.5 \\
\hline \multirow[t]{2}{*}{ OLZ vs RIS } & 70.9 & $69.2^{\mathrm{a}}$ & $67.1^{a}$ & $65.4^{\mathrm{a}}$ & $63.7^{\mathrm{a}}$ & $62.2^{\mathrm{a}}$ & $60.8^{a}$ & 58.8 \\
\hline & 64.7 & 62.1 & 59.6 & 58.3 & 56.6 & 54 & 53.2 & 51.9 \\
\hline \multirow[t]{2}{*}{ OLZ vs QUE } & $70.9^{b}$ & $69.2^{\mathrm{a}}$ & $67.1^{\mathrm{a}}$ & $65.4^{\mathrm{a}}$ & $63.7^{\mathrm{a}}$ & $62.2^{\mathrm{a}}$ & $60.8^{\mathrm{a}}$ & $58.8^{\mathrm{a}}$ \\
\hline & 56.3 & 56.3 & 54.5 & 54.5 & 51.8 & 49.1 & 46.4 & 46.4 \\
\hline \multirow[t]{2}{*}{ RIS vs QUE } & 64.7 & 62.1 & 59.6 & 58.3 & 56.6 & 54 & 53.2 & 51.9 \\
\hline & 56.3 & 56.3 & 54.5 & 54.5 & 51.8 & 49.1 & 46.4 & 46.4 \\
\hline \multirow[t]{2}{*}{ CLO vs HAL } & $79.7^{c}$ & $78.4^{c}$ & $78.4^{c}$ & $77^{c}$ & $77^{c}$ & $77^{c}$ & $75.7^{c}$ & $75.7^{c}$ \\
\hline & 42.7 & 41.8 & 38.2 & 37.3 & 34.5 & 29.1 & 29.1 & 24.5 \\
\hline \multirow[t]{2}{*}{ CLO vs RIS } & $79.7^{\mathrm{a}}$ & $78.4^{\mathrm{a}}$ & $78.4^{\mathrm{a}}$ & $77^{\mathrm{b}}$ & $77^{\mathrm{b}}$ & $77^{\mathrm{b}}$ & $75.7^{\mathrm{b}}$ & $75.7^{\mathrm{b}}$ \\
\hline & 64.7 & 62.1 & 59.6 & 58.3 & 56.6 & 54 & 53.2 & 51.9 \\
\hline \multirow[t]{2}{*}{ CLO vs OLZ } & 79.7 & 78.4 & 78.4 & 77 & 77 & 77 & 75.7 & $75.7^{\mathrm{a}}$ \\
\hline & 70.9 & 69.2 & 67.1 & 65.4 & 63.7 & 62.2 & 60.8 & 58.8 \\
\hline \multirow[t]{2}{*}{ CLO vs QUE } & $79.7^{b}$ & $78.4^{\mathrm{a}}$ & $78.4^{b}$ & $77^{a}$ & $77^{\mathrm{b}}$ & $77^{\mathrm{b}}$ & $75.7^{\mathrm{b}}$ & $75.7^{b}$ \\
\hline & 56.3 & 56.3 & 54.5 & 54.5 & 51.8 & 49.1 & 46.4 & 46.4 \\
\hline
\end{tabular}

Sample size: Haloperidol $n=110 ;$ OLZ $n=347 ;$ RIS $n=235$; QUE $n=112 ;$ CLO $n=74$.

asignificant groups difference at $\mathrm{p}<0.05$.

bSignificant groups difference at $\mathrm{p}<0.01$.

'Significant groups difference at $\mathrm{p}<0.001$.

Abbreviations: MPR, medication possession ratio; CLO, clozapine; HAL, haloperidol; OLZ, olanzapine; QUE, quetiapine; RIS, risperidone.

95\% CI 1.29-3.40, $\mathrm{p}=0.003)$ and olanzapine-treated patients $(\mathrm{HR}=1.35,95 \%$ CI $1.04-1.74, \mathrm{p}=0.023)$. The quetiapinetreatment group was more likely to discontinue medication compared to clozapine $(\mathrm{HR}=2.24,95 \%$ CI $1.29-3.88$, $\mathrm{p}=0.004)$ and olanzapine-treated patients $(\mathrm{HR}=1.55,95 \%$ CI 1.09-2.20, p =0.014). Hazard ratios were statistically significant except for the comparison between risperidone and quetiapine $(\mathrm{HR}=1.21,95 \%$ CI $0.86-1.70, \mathrm{p}=0.285)$.

\section{Adherence and persistence}

The MPR-based adherence measure was highly and significantly correlated with the persistent measure - time to all-cause medication discontinuation $(r=0.957, n=878$, $\mathrm{p}<0.001)$.

\section{Discussion}

In this large, prospective, naturalistic, nonrandomized study of schizophrenia patients, as in several other studies (Fenton et al 1997; Cramer and Rosenheck 1998; Gilmer et al 2004), only about half of the patients (58\%) were found to be adherent to antipsychotic regimens. Adherence was, however, especially poor for patients treated with the typical antipsychotic haloperidol. Only $35 \%$ of the patients treated with haloperidol were found to be adherent compared to $61 \%$ of the patients treated with atypicals. The atypicals were not all alike, and among the studied atypicals, clozapine therapy was associated with highest rate of adherence (77\%) followed by olanzapine (64\%), risperidone (57\%), and quetiapine (52\%) therapy. Although rates of adherence with atypicals appear significantly higher than with the typical antipsychotic, these are still suboptimal adherence rates, as a large proportion of the patients remain poorly adherent with their medication regimens.

In addition to replicating previous findings (Svarstad et al 2001; Al-Zarkawi et al 2003; Menzin et al 2003; Mojtabie et al 2003; Opolka et al 2003; Gibson et al 2004), our study expands the literature by showing differential adherence among 4 atypical agents and a descending order in adherence levels: clozapine, olanzapine, risperidone, and quetiapine, with similar and intermediate levels of adherence for risperidone- and quetiapine-treated patients. Moreover, haloperidol was associated with the poorest level of adherence and persistence despite its use in moderate doses (mean dose $8.8 \mathrm{mg} /$ day). This is of interest because most industry-sponsored clinical trials have compared atypical antipsychotics with haloperidol in higher doses, a practice that was considered by some (Geddes et al 2000; Rosenheck 2005) to have biased the results in favor of the newer agents. The present findings appear consistent with the meta-analysis by Davis et al (2003), which showed that the dose of haloperidol did not bias the findings that favored the atypicals over the typicals. 
While haloperidol was prescribed in moderate doses, quetiapine was prescribed in relatively low doses (mean $331.6 \mathrm{mg} /$ day). This dose appears, however, to reflect medication use pattern of quetiapine in usual practice in the US. This was previously shown in a large claims database study of schizophrenia patients treated in the US (Gianfrancesco et al 2006) that was sponsored by the manufacturer of quetiapine. Using 7017 treatment episodes during a period from January 1999 through August 2003, the study reported the mean dose of quetiapine to be $264 \mathrm{mg}$ /day, suggesting that our findings reflect usual treatment pattern with quetiapine in the US, at least during the study period.

Although the current adherence-related findings are consistent with several previous studies, they are also inconsistent with some others (Dolder et al 2002; Søholm and Lublin 2003; Gilmer et al 2004; Valenstein et al 2004; Joyce et al 2005; Gianfrancesco et al 2006). The reasons for the inconsistent findings are unclear, but may stem from methodological issues such as differences in adherence measures, study designs, patient populations, cross-sectional approach that compares treatment groups independently of the time of initiation on the medication, lack of uniform period of follow-up, and use of different approaches to controlling for selection effects, and the potential pre-existing differences between the treatment groups.

The present study also shows - for the first time - a high and significant level of concordance between adherence and persistence with the medication in the same population, suggesting that the two measures may be interchangeable. It is unclear, however, if both parameters are indeed measuring the same thing, since we used a proxy measure of adherence (did not observe if patients were taking the medications as directed in the prescribed dosage, schedule, and method of ingestion) and did not assess medication acceptance, which may impact both adherence and persistence.

Mirroring results from the adherence-based analyses, persistence level was poorer with haloperidol compared to the four combined atypicals with a similar descending order in persistence levels: clozapine, olanzapine, risperidone, quetiapine, and haloperidol, and with similar and intermediate levels of persistence for the risperidone- and quetiapinetreatment groups. These findings are consistent with previous research demonstrating better persistence with clozapine (Ascher-Svanum et al 2006b; McEvoy et al 2006; Haro et al 2007) compared to olanzapine, risperidone, quetiapine, and typical antipsychotics and better persistence with olanzapine compared to haloperidol (Revicki et al 1999; Glick and Berg 2002; Ren et al 2002; Lieberman et al 2003; Dossenbach et al 2004; Tiihonen et al 2006; Ascher-Svanum et al 2006b; Tunis et al 2006), risperidone (Gilbody et al 2000; Bagnall et al 2003; Leucht et al 2003; Santarlasci and Messori 2003; Dossenbach et al 2004; Pelagotti et al 2004; Breier et al 2005; Lieberman et al 2005; Ascher-Svanum et al 2006b; Beasley et al 2007; Cooper et al 2007; Haro et al 2007; Jayaram et al 2007; Tunis et al 2006; Beasley et al 2007; Haro et al 2007), and quetiapine (Dossenbach et al 2004; Lieberman 2005; Ascher-Svanum et al 2006b; Kinon et al 2006b; McEvoy et al 2006; Stroup et al 2006; Beasley et al 2007; Haro et al 2007; Mullins et al 2007). Furthermore, as we hypothesized based on CATIE phase 1 findings (Lieberman et al 2005), no significant differences were found on persistence or adherence between the risperidone and quetiapine treatment groups.

The observed concordance between adherence and persistence with antipsychotics has important ramifications for schizophrenia research and for clinical practice due to growing recognition that persistence with antipsychotics is a global proxy measure of a medication's effectiveness (Lieberman et al 2005) and more importantly because both medication adherence and persistence are associated with beneficial outcomes in the long-term treatment of patients with schizophrenia. Furthermore, the favorable outcomes associated with medication adherence are likely applicable to findings of persistence studies. This extrapolation needs, however, to be further studied across adherence measures, beyond the MPR measure.

The strengths of our study appear to lie in its large, diverse, and representative sample; the ability to provide comparative data on a number of commonly used antipsychotics; the availability of medication information during hospitalizations (a type of data that is typically absent in claims databases); and notably, the ability to generalize the findings to patients treated in large public systems of care across the US.

Our study has, however, a number of limitations. First is the potential for selection bias due to the naturalistic, nonrandomized design of the study in which the treatment groups significantly differed on a number of variables at the time of initiation of the medication. Despite our use of statistical adjustments for observed group differences, other residual imbalances due to unobservable factors could have been present and hampered the comparisons. Although we cannot eliminate the possibility of selection bias, it is important to note that the current findings are consistent with a large body of prior research - about 29 studies - that differs in study design and world geographies and include the NIMH-sponsored CATIE (Lieberman et al 2005; McEvoy 2006; Stroup et al 2006) as 
well as other randomized, double-blind, controlled trials in which selection bias is largely eliminated (Revicki et al 1999; Santarlasci and Messori 2003; Kemmler et al 2005; Beasley et al 2007; Jayaram et al 2007; Kinon et al 2006a, b).

Lack of information about the reasons for medication discontinuation is another study limitation. Our study was not designed to assess reasons for initiation or discontinuation of the antipsychotic medications, thus lacking this clinically important information. It is notable, however, that time to medication discontinuation for any cause was chosen by the NIMH-Sponsored CATIE trials to be the primary outcome measure, as this global index is said to reflect a medication efficacy, safety, and tolerability from both patient and clinician perspectives (Stroup et al 2003; Lieberman et al 2005).

Another study limitation is the use of prescription, rather than pharmacy fill data to assess adherence and persistence. Previous research (Svarstad et al 2001) has demonstrated, however, a high level of agreement between prescription rate and pharmacy fill rate in this severely ill population. Moreover, several MPR findings in the present prescriptionbased study were consistent with pharmacy fill-based MPR findings in previous studies (Svarstad et al 2001; Zhao et al 2002; Opolka et al 2003; Rascati et al 2003; Gibson et al 2004), suggesting that the two measures are highly correlated. Of special note is a study of Michigan Medicaid pharmacy database (Gibson et al 2004) showing higher adherence rates for olanzapine- than risperidone-treated patients ( $60 \%$ vs $54 \%$, $\mathrm{p}<0.01)$, a finding that was almost identical to ours $(63.7 \%$ vs $56.6 \%, \mathrm{p}<0.05)$. That study also reported an adherence rate on haloperidol (37\%) that was very similar to that found in the current study (34.5\%). Thus, although the current analysis used prescription data, results were similar to those based on pharmacy fill data, helping to bolster confidence in the validity of the current findings. An additional study limitation is lack of control for potential "sponsor" bias that could have influenced clinicians' medication use patterns in favor of the sponsor's antipsychotic medication (olanzapine). Although we cannot rule out this possibility, the results of the present study are consistent with previous results reported by researchers who used nonindustry-sponsored data such as Medicaid claims databases (Opolka et al 2003; Rascati et al 2003; Gibson et al 2004) and with results from independent, nonindustry-sponsored studies (Gilbody et al 2000; Bagnall et al 2003; Leucht et al 2003; Kemmler et al 2005; Lieberman 2005; Cooper et al 2007).

Current findings demonstrate that atypical agents are not all alike on medication adherence and persistence suggesting that the choice of antipsychotic agent may be an important factor that impacts treatment adherence and persistence, thus the long-term treatment outcomes during usual care of patients with schizophrenia. Although this study found better adherence and persistence with atypicals, and among the atypicals with clozapine and olanzapine, it is important to note that at its best the overall level of adherence (and persistence) with the medication was still suboptimal, thus requiring diligent identification of the poorly adherent patients and the provision of relevant and effective adherence interventions to help enhance these patients' long-term outcomes. Current findings are based on a large and diverse group of patients that varied in health care delivery systems, geography, ethnicity, gender, and illness severity, a diversity that may facilitate generalization of the findings to schizophrenia patients treated across the US. Future studies are needed to replicate the findings and to identify the reasons that drive better adherence and persistence with specific antipsychotics in order to help tailor individualized adherence improvement strategies for patients who are poorly adherent with their antipsychotic regimens.

\section{Acknowledgments}

The US-SCAP study was supported by Eli Lilly and Company and administered by the Medstat Group. We wish to thank the site investigators and others who collaborated in the US-SCAP study: Barrio C, PhD, Center for Research on Child and Adolescent Mental Health Services, San Diego, CA; Dunn LA, MD, Duke University Medical Center Department of Psychiatry, Durham, NC; Gallucci G, MD, (previously) Johns Hopkins Bayview Medical Center and the University of Maryland Medical Systems, Baltimore, MD; Garcia P, PhD, Center for Research on Child and Adolescent Mental Health Services, San Diego, CA; Harding C, PhD, Boston University and Community Mental Health Centers in Denver, CO; Hoff R, PhD, MPH, West Haven Veteran's Administration Medical Center (VAMC) and the Connecticut Mental Health Center (CMHC), West Haven, CT; Hough R, PhD, Center for Research on Child and Adolescent Mental Health Services California, San Diego, CA; Lehman AF, MD, Johns Hopkins Bayview Medical Center and the University of Maryland Medical Systems, Baltimore, MD; Palmer L, PhD, The Medstat Group, Inc, Washington, DC; Rosenheck RA, MD, West Haven Veteran's Administration Medical Center (VAMC) and the Connecticut Mental Health Center (CMHC), West Haven, CT; Russo P, PhD, MSW, RN, (Previously) The Medstat Group, Inc, Washington, DC; Salkever D, PhD, (previously) Johns Hopkins University, 
Department of Health Policy and Management, Baltimore, MD; Saunders T, MS, Drug Abuse and Mental Health Program Office of District 7 and University of South Florida's Florida Mental Health Institute, Orlando, FL; Shumway M, PhD, University of California at San Francisco, Department of Psychiatry, San Francisco, CA; Shern D, PhD, (previously) Drug Abuse and Mental Health Program Office of District 7 and University of South Florida's Florida Mental Health Institute, Orlando, FL; Slade E, PhD, (previously) Johns Hopkins University, Department of Health Policy and Management, Baltimore, MD; Swartz M, MD, Duke University Medical Center, Department of Psychiatry, Durham, NC; Swanson J, PhD, Duke University Medical Center Department of Psychiatry, Durham, NC.

\section{References}

Al-Zakwani IS, Barron JJ, Bullano MF, et al. 2003. Analysis of healthcare utilization patterns and adherence in patients receiving typical and atypical antipsychotic medications. Curr Med Res Opin, 19:619-26.

Ascher-Svanum H, Zhu B, Faries D, et al. 2004. A comparison of olanzapine and risperidone on the risk of psychiatric hospitalization in the naturalistic treatment of patients with schizophrenia. Ann Gen Hosp Psychiatry, 3:11.

Ascher-Svanum H, Faries DE, Zhu B, et al. 2006a. Medication adherence and long-term functional outcomes in the treatment of schizophrenia in usual care. J Clin Psychiatry, 67:453-60.

Ascher-Svanum H, Zhu B, Faries D, et al. 2006b. Time to discontinuation of atypical versus typical antipsychotics in the naturalistic treatment of schizophrenia. BMC Psychiatry, 6:8.

Bagnall AM, Jones L, Ginnelly L, et al. 2003. A systematic review of atypical antipsychotic drugs in schizophrenia. Health Technol Assess, 7:1-193. URL: http://www.ncchta.org/project.asp?PjtId = 1235 Health Technology Assessment (HTA) on behalf of the National Institute for Clinical Excellence (NICE) in the UK.

Beasley CM, Stauffer VL, Liu-Seifert H, et al. 2007. All-cause treatment discontinuation in schizophrenia during treatment with olanzapine relative to other antipsychotics: an integrated analysis. J Clin Psychopharmacol, 27:252-8.

Box GEP, Cox DR. 1964. An analysis of transformations. Journal of the Royal Statistical Society, 26:211-43.

Breier A, Berg PH, Thakore JH, et al. 2005. Olanzapine versus ziprasidone: results of a 28-week double-blind study in patients with schizophrenia. Am J Psychiatry, 162:1879-1887.

Cooper D, Moisan J, Gregoire JP. 2007. Adherence to atypical antipsychotic treatment among newly treated patients: a population-based study in schizophrenia. J Clin Psychiatry, 68:818-25.

Cramer JA, Rosenheck R. 1998. Compliance with medication regimens for mental and physical disorders. Psychiatr Serv, 49:196-201.

Davis JM, Chen N, Glick ID. 2003. A meta-analysis of the efficacy of second-generation antipsychotics. Arch Gen Psychiatry, 60:553-64.

Diaz E, Neuse E, Sullivan MC, et al. 2004. Adherence to conventional and atypical antipsychotics after hospital discharge. J Clin Psychiatry, 65:354-360.

Dolder CR, Lacro JP, Dunn LB, et al. 2002. Antipsychotic medication adherence: is there a difference between typical and atypical agents? Am J Psychiatry, 159:103-8.

Dossenbach M, Erol A, el Mahfoud Kessaci M, et al. 2004. Effectiveness of antipsychotic treatments for schizophrenia: interim 6-month analysis from a prospective observational study (IC-SOHO) comparing olanzapine, quetiapine, risperidone, and haloperidol. J Clin Psychiatry, $65: 312-21$.
Elbogen EB, Swanson JW, Swartz MS, et al. 2005. Medication nonadherence and substance abuse in psychotic disorders: impact of depressive symptoms and social stability. J Nerv Ment Dis, 193:673-9.

Faries D, Ascher-Svanum H, Zhu B, et al. 2005. Antipsychotic monotherapy and polypharmacy in the naturalistic treatment of schizophrenia with atypical antipsychotics. BMC Psychiatry, 5:26.

Fenton WS, Blyler CR, Heinssen RK. 1997. Determinants of medication compliance in schizophrenia: empirical and clinical findings. Schizophr Bull, 23:637-51.

Garcia-Cabeza I, Gomez JC, Sacristan JA, et al. 2001. Subjective response to antipsychotic treatment and compliance in schizophrenia. A naturalistic study comparing olanzapine, risperidone and haloperidol (EFESO Study). BMC Psychiatry, 1:7.

Geddes J, Freemantle N, Harrison P, et al. 2000. Atypical antipsychotics in the treatment of schizophrenia: systematic overview and metaregression analysis. $B M J, 321: 1371-6$.

Gianfrancesco FD, Rajagopalan K, Sajatovic M, et al. 2006. Treatment adherence among patients with schizophrenia treated with atypical and typical antipsychotics. Psychiatry Res, 144:177-89.

Gibson PJ, Damler R, Jackson EA, et al. 2004. The impact of olanzapine, risperidone, or haloperidol on the cost of schizophrenia care in a medicaid population. Value Health, 7:22-35.

Gilbody SM, Bagnall AM, Duggan L, et al. 2000. Risperidone versus other atypical antipsychotic medication for schizophrenia. Cochran Database Syst Rev, 3:CD002306.

Gilmer TP, Dolder CR, Lacro JP, et al. 2004. Adherence to treatment with antipsychotic medication and health care costs among Medicaid beneficiaries with schizophrenia. Am J Psychiatry, 161:692-9.

Glick ID, Berg PH. 2002. Time to study discontinuation, relapse, and compliance with atypical or conventional antipsychotics in schizophrenia and related disorders. Int Clin Psychopharmacol, 17:65-8.

Haro JM, Suarez D, Novick D, et al. 2007. Three-year antipsychotic effectiveness in the outpatient care of schizophrenia: observational versus randomized studies results. Eur Neuropsychopharmacol, 17:235-44.

Jayaram MB, Hosalli PM, Stroup TS. 2007. Risperidone versus olanzapine for treatment of schizophrenia. Schizophr Bull, 33:1274-6.

Jones PB, Barnes TR, Davies L, et al. 2006. Randomized controlled trial of the effect on Quality of Life of second- vs first-generation antipsychotic drugs in schizophrenia: Cost Utility of the Latest Antipsychotic Drugs in Schizophrenia Study (CUtLASS 1). Arch Gen Psychiatry, 63:1079-87.

Joyce AT, Harrison DJ, Loebel AD, et al. 2005. Impact of atypical antipsychotics on outcomes of care in schizophrenia. Am J Manag Care, 11:S254-61.

Kampman O, Lehtinen K. 1999. Compliance in psychoses. Acta Psychiatr Scand, 100:167-75.

Kemmler G, Hummer M, Widschwendter C, et al. 2005. Dropout rates in placebo-controlled and active-control clinical trials of antipsychotic drugs: a meta-analysis. Arch Gen Psychiatry, 62:1305-12.

Kinon BJ, Lipkovich I, Edwards SB, et al. 2006a. A 24-week randomized study of olanzapine versus ziprasidone in the treatment of schizophrenia or schizoaffective disorder in patients with prominent depressive symptoms. J Clin Psychopharmacol, 26:157-62.

Kinon BJ, Noordsy DL, Liu-Seifert H, et al. 2006b. Randomized doubleblind 6-month comparison of olanzapine and quetiapine in patients with schizophrenia or schizoaffective disorder with prominent negative symptoms and poor functioning. J Clin Psychopharmacol, 26:453-61.

Leucht S, Barnes TR, Kissling W, et al. 2003. Relapse prevention in schizophrenia with new-generation antipsychotics: a systematic review and exploratory meta-analysis of randomized, controlled trials. Am J Psychiatry, 160:1209-22.

Lieberman JA, Tollefson G, Tohen M, et al. 2003. Comparative efficacy and safety of atypical and conventional antipsychotic drugs in firstepisode psychosis: a randomized, double-blind trial of olanzapine versus haloperidol. Am J Psychiatry, 160:1396-404. 
Lieberman JA, Stroup TS, McEvoy JP, et al. 2005. Effectiveness of antipsychotic drugs in patients with chronic schizophrenia. N Engl J Med, 353:1209-23.

McEvoy JP, Lieberman JA, Stroup TS, et al. 2006. Effectiveness of clozapine versus olanzapine, quetiapine, and risperidone in patients with chronic schizophrenia who did not respond to prior atypical antipsychotic treatment. Am J Psychiatry, 163:600-10.

Menzin J, Boulanger L, Friedman M, et al. 2003. Treatment adherence associated with conventional and atypical antipsychotics in a large state Medicaid program. Psychiatr Serv, 54:719-23.

Mojtabai R, Lavelle J, Gibson PJ, et al. 2003. Atypical antipsychotics in first admission schizophrenia: medication continuation and outcomes. Schizophr Bull, 29:519-30.

Mudge NAC, Davey PJ, Coleman KA, et al. 2005. A comparison of olanzapine versus risperidone for the treatment of schizophrenia-a meta analysis of randomized clinical trials. Int J Psychiatr Clin Pract, 9:3-15.

Mullins CD, Obeidat NA, Cuffel BJ, et al. 2007. Risk of discontinuation of atypical antipsychotic agents in the treatment of schizophrenia. Schizophr Res, [Epub ahead of print].

Opolka JL, Rascati KL, Brown CM, et al. 2003. Role of ethnicity in predicting antipsychotic medication adherence. Ann Pharmacother, 37:625-30.

Pelagotti F, Santarlasci B, Vacca F, et al. 2004. Dropout rates with olanzapine or risperidone: a multi-centre observational study. Eur J Clin Pharmacol, 59:905-9.

PhRMA clinicalstudyresults.org website. URL: http://www.clinicalstudyresults.org/documents/company-study_509_1.pdf Aripiprazole/BMS Clinical Study Report CN138003

Rascati KL, Johnsrud MT, Crismon ML, et al. 2003. Olanzapine versus risperidone in the treatment of schizophrenia: a comparison of costs among Texas Medicaid recipients. Pharmacoeconomics, 21:683-97.

Ren XS, Kazis LE, Lee AF, et al. 2002. Patient characteristics and prescription patterns of atypical antipsychotics among patients with schizophrenia. J Clin Pharm Ther, 27:441-51.

Revicki DA, Genduso LA, Hamilton SH, et al. 1999. Olanzapine versus haloperidol in the treatment of schizophrenia and other psychotic disorders: quality of life and clinical outcomes of a randomized clinical trial. Qual Life Res, 8:417-26.

Rosenheck R, Perlick D, Bingham S, et al. 2003. Effectiveness and cost of olanzapine and haloperidol in the treatment of schizophrenia: a randomized controlled trial. JAMA, 290:2693-702.

Rosenheck RA. 2005. Open forum: effectiveness versus efficacy of secondgeneration antipsychotics: haloperidol without anticholinergics as a comparator. Psychiatr Serv, 56:85-92.

Rosenheck RA, Leslie DL, Sindelar J, et al. 2006. Cost-effectiveness of second-generation antipsychotics and perphenazine in a randomized trial of treatment for chronic schizophrenia. Am J Psychiatry, 163:2080-9.

Santarlasci B, Messori A. 2003. Clinical trial response and dropout rates with olanzapine versus risperidone. Ann Pharmacother, 37:556-63.

Simpson GM, Glick ID, Weiden PJ, et al. 2004. Randomized, controlled, double-blind multicenter comparison of the efficacy and tolerability of ziprasidone and olanzapine in acutely ill inpatients with schizophrenia or schizoaffective disorder. Am J Psychiatry, 161:1837-47.
Søholm B, Lublin H. 2003. Long-term effectiveness of risperidone and olanzapine in resistant or intolerant schizophrenic patients. A mirror study. Acta Psychiatr Scand, 107:344-50.

Strom BL, Faich G, Eng E, et al. 2007. Comparative Mortality Associated with Ziprasidone vs Olanzapine in Real-World Use: The Ziprasidone Observational Study of Cardiac Outcomes (ZODIAC). Presented at the 46th annual meeting of the American College of Neuropsychopharmacology (ACNP), December 12, 2007, Boca Raton, FL.

Stroup TS, McEvoy JP, Swartz MS, et al. 2003. The National Institute of Mental Health Clinical Antipsychotic Trials of Intervention Effectiveness (CATIE) project: schizophrenia trial design and protocol development. Schizophr Bull, 29:15-31.

Stroup TS, Lieberman JA, McEvoy JP, et al. 2006. Effectiveness of olanzapine, quetiapine, risperidone, and ziprasidone in patients with chronic schizophrenia following discontinuation of a previous atypical antipsychotic. Am J Psychiatry, 163:611-22.

Svarstad BL, Shireman TI, Sweeney JK. 2001. Using drug claims data to assess the relationship of medication adherence with hospitalization and costs. Psychiatr Serv, 52:805-11.

Swanson JW, Swartz MS, Elbogen EB, et al. 2004a. Reducing violence risk in persons with schizophrenia: olanzapine versus risperidone. J Clin Psychiatry, 65:1666-73.

Swanson JW, Swartz MS, Elbogen EB. 2004b. Effectiveness of atypical antipsychotic medications in reducing violent behavior among persons with schizophrenia in community-based treatment. Schizophr Bull, 30:3-20.

Thieda P, Beard S, Richter A, et al. 2003. An economic review of compliance with medication therapy in the treatment of schizophrenia. Psychiatr Serv, 54:508-16.

Tiihonen J, Walhbeck K, Lönnqvist J, et al. 2006. Effectiveness of antipsychotic treatments in a nationwide cohort of patients in community care after first hospitalisation due to schizophrenia and schizoaffective disorder: observational follow-up study. BMJ, 333:224.

Tunis SL, Faries DE, Nyhuis AW, et al. 2006. Cost-effectiveness of olanzapine as first-line treatment for schizophrenia: results from a randomized, open-label, 1-year trial. Value Health, 9:77-89.

Valenstein M, Copeland LA, Blow FC, et al. 2002. Pharmacy data identify poorly adherent patients with schizophrenia at increased risk for admission. Med Care, 40:630-9.

Valenstein M, Blow FC, Copeland LA, et al. 2004. Poor antipsychotic adherence among patients with schizophrenia: medication and patient factors. Schizophr Bull, 30:255-64.

Weiden PJ, Kozma C, Grogg A, et al. 2004. Partial compliance and risk of rehospitalization among California Medicaid patients with schizophrenia. Psychiatr Serv, 55:886-91.

Zhao Z, Tunis SL, Lage M. 2002. Mediation treatment patterns following initiation on olanzapine versus risperidone. Clin Drug Invest, 22:741-9. 
